\title{
Logistic Controlling Processes and Quality Issues in a Cast Iron Foundry
}

\author{
ULEWICZ Robert', a, MAZUR Magdalena1, b *, KNOP Krzysztof ${ }^{1, c}$ \\ and DWORNICKA Renata2, d \\ ${ }^{1}$ Czestochowa University of Technology, J.H. Dabrowskiego 69, 42-201 Czestochowa, Poland \\ ${ }^{2}$ Krakow University of Technology, Warszawska 24, 31-155 Krakow, Poland \\ a robert.ulewicz@pcz.pl, b magdalena.mazur@pcz.pl, ckrzysztof.knop@pcz.pl, \\ drenata.dwornicka@mech.pk.edu.pl
}

Keywords: Iron Foundry, Quality, Process, Logistics, Controlling, Work Ergonomics

\begin{abstract}
The article shows issues related to the creation and implementation of added value through logistics and processing in a cast iron foundry. The possibilities of improving the casting production systems through the assessment of their labor consumption and the analysis of manufacturing prime costs were discussed. In order to increase the efficiency of iron foundry management, quality control was introduced. The comparative method was used in the studies presented here. Two areas of organization management were compared: the quality management area and the financial management area. The purpose of this comparison is to find common features when supervising tasks in both zones.
\end{abstract}

\section{Introduction}

The activity of a person managing the process comes down to transforming resources into a desired effect in such a way as to meet the requirements, while the control should be understood as the activity aimed at ensuring the desired course of the process [1]. The final effect of the company's work may take various forms, and one of the basic effects of starting a production activity are generally understood products. High quality of products can be achieved, among others by building a measurement and control system in a manner enabling the generation of information related to the company's needs or the needs of the system monitoring the company's situation $[2,3]$.

For most companies, high-quality delivery is a key area that determines the production process. In the presented case, quality is the rhythm of deliveries as well as the quantity and technical parameters in accordance with the orders. On the other hand, sales is an area that determines the company's market success. In this perspective, purchasing and selling represent two extreme activities of the company. The first one determines the commencement of production within a strictly defined deadline, provided that the appropriate input material is obtained. The second enables an organized co-operation with recipients. In both cases, it is necessary to ensure efficient control of logistics processes, elimination of interruptions, delays in order fulfillment, etc. Optimizing the involvement of stock and capital usually leads to lowering running costs and increasing their fluctuation, especially when the manufactured product is an industrial product, e.g. a cast mold, where a significant part of the total cost (about 50\%) is related to the material.

\section{The quality of the supply chain}

The quality of the supply chain must be considered from the very beginning. In the case of iron foundries, the logistic chain of supplier-foundry-customer may be of a different nature due to the 
specificity of production [4]. Here you can deal with long-term contracts covering both serial production and complex individual castings. In both cases, however, key elements can be identified:

- product quality depends on the quality of raw materials, materials and semi-finished products,

- the quality of information flow and the level of customer service.

In the conditions of fierce competition on the market of foundry products, apart from good quality castings, customer service is also important, depending on logistic processes in the area of customer service. Only a product that meets customer expectations and customer service alone is able to provide the company with a competitive advantage. Many companies, in order to improve their competitiveness, create meta-logistics chains, which is one of the key issues in the uniform understanding of quality.

The problem is quite serious because, in common terminology, a 'defect' triggers procedures, control system check-ups, possibly misunderstandings, downtime, deadline failures and thus generates financial losses. In solving this problem, the management system leaned on ISO 9001 is very helpful, in which the authors introduced a trial approach with the definition of an internal customer and an external customer [5].

The use of comprehensive management includes essential elements of TQM, and the goal is to ensure high quality parameters of raw materials, materials, semi-finished products and final products. If the quality level of these products is high, the logistics system will also achieve its goals: cost reduction, inventory reduction, storage space reduction.

\section{Controlling of logistics processes}

Controlling is the only logical and concise response to the processes taking place in the company and its environment. Material flows as well as production and management processes play an important role $[6,7]$. The controlling system compares the standard defined by the schedule and plan with the actual state, taking into account the economic dimension of the existing derivations. A comparative assessment of the actual and the assumed state may bring two results:

a) first - when the actual state meets the limitations of the standard (no corrective actions) and

b) second - when the actual condition does not meet the limits of the standard (corrective actions should be taken) [8].

The controlling department, using the available information, analyzes to what extent the production status depends on the stock levels, human resources, development research, available technologies and the market situation. Fig. 1 shows controlling in the analyzed company against the background of key areas.

In order to be able to speak of universal controlling, it is first necessary to present four basic procedures that will have to be carried out regardless of where controlling is introduced. These treatments include:

a) procedure " 0 " - building the controlling base. This procedure covers both the reporting part and the control. In particular, the first one produces market technical and organizational indicators, as well as financial reporting related to the total effect basic items, capital flows and income statement related to the basic total effect items, capital flows and profit and loss ratios.

b) procedure " 1 " - organizational and information security of the controlling system in the company's organizational structures. This procedure concerns determining the scope of responsibility for creating a base of individual controlling services, keeping records and actual monitoring of the size, as well as calculating and analyzing gagers size deviations: indicators 
of the technical and organizational market plan, indicators, financial reporting, control indicators.

c) procedure " 2 " - determination of the level of acceptable deviations of indicators used in the controlling system. This procedure concerns the determination of acceptable deviations of the baseline indicators. It shows a variant approach to creating an acceptable limit method.

d) procedure " 3 " - corrective actions. This procedure pertains to deciding on an acceptable gager size. When the amount of deviation from the base is measured, at least the cause of this phenomenon must be determined within a legal interval.

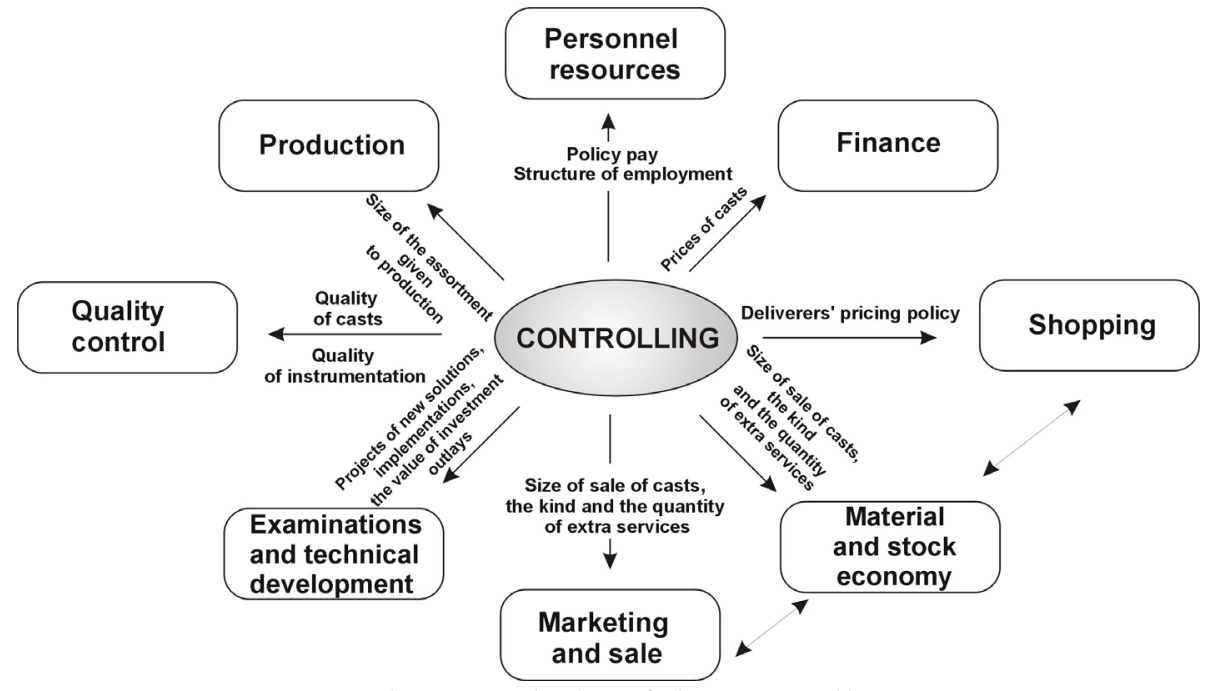

Figure 1. The main links of the controlling system influencing the logistic processes of purchasing and sales

When designing controlling procedures, the logistics system may use the following gagers:

a) level of the customer's service

- state of material provisions,

- state of provisions of production in progress,

- state of provisions of final goods,

- state of the physical flow of materials,

- state of computer processes,

b) market position

- market share in basic assortments,

- market share in all assortments,

- changes in the market share in general,

- valuable participation of own logistic processes in demand for logistics in general;

c) remunerativeness

- level of expenses of logistics,

- participation of expenses of logistics in expenses of producing,

- level of producing expenses,

- level of sale expenses,

- income in general,

- remunerativeness of logistics,

- remunerativeness of producing. 


\section{Controlling of the quality}

The research used the methodology described by Polak [9], and the techniques of document examination, interview and participant observation were used to collect the data. The following documents were analyzed: processes, supplementary order cards, audit reports, proxy quality plans, quality reports, reports on quality council sessions and supervisory board meetings, and financial reporting. The following action plan was established:

- defining aspects and goals,

- planning the implementation of activities,

- implementation of activities,

- control of the implementation of activities,

- analysis of the final results and summary.

In the first stage of work, the goals of the organization were defined in terms of quality, environment, work safety and finances. Risky spots were created in the implementation of the enterprise in relation to standards, regulations regarding the rights and expectations of the client. Properly identified aspects define the goals of the organization and related processes. Properly identified aspects define the goals of the organization, as well as processes related to them. Usually, these are separate goals concerning quality, environment, work safety and finances, which simplifies the delegation of responsibility and controlling. It is not recommended to combine goals in all spheres of management. When planning quality tasks for the entire organization, the proxy determines the main priorities: periodic reviews, audits, corrective tasks. The final stage of activities results in an annual report containing breakdowns and existing threats. The report should include an analysis of management effectiveness and measures to improve the quality of management. A similar plan of action also applies to the sphere of financial management. There are two boards in the area of quality and finance: the quality board oversees the achievement of universal goals, and the supervisory board oversees the achievement of results-oriented goals. There is a great similarity in controlling, operating in the sphere of quality management and in the financial sphere, which creates the possibility of quick integration of these spheres. Table 1 presents a comparison of the sphere of quality and the sphere of finance.

Table 1. Comparison of financial sphere and qualities.

\begin{tabular}{c|c|c|c}
\hline \multirow{2}{*}{ Element } & Defining of element & $\begin{array}{c}\text { Quality management } \\
\text { zone }\end{array}$ & $\begin{array}{c}\text { Finance management } \\
\text { zone }\end{array}$ \\
\hline \multirow{2}{*}{$\begin{array}{c}\text { Responsibility for } \\
\text { controlling process }\end{array}$} & Initiator & $\begin{array}{c}\text { Management proxy of } \\
\text { quality system }\end{array}$ & Finance controller \\
\cline { 2 - 4 } & References center & Quality board & Chairmen board \\
\cline { 2 - 4 } Tools & Recipient & External auditor & Accountant \\
\hline \multirow{2}{*}{$\begin{array}{c}\text { Documents related to } \\
\text { controlling process }\end{array}$} & Initiating & $\begin{array}{c}\text { Audit, inspection, } \\
\text { periodical survey. }\end{array}$ & $\begin{array}{c}\text { Stock-taking, } \\
\text { inventory, survey }\end{array}$ \\
\cline { 2 - 4 } & Periodical survey & Quality plan & Finance plan \\
\cline { 2 - 4 } & Finalizing & Quality state report & Finance report \\
\cline { 2 - 4 } & Improving & \multicolumn{2}{|c|}{ Business plan balance } \\
\hline
\end{tabular}




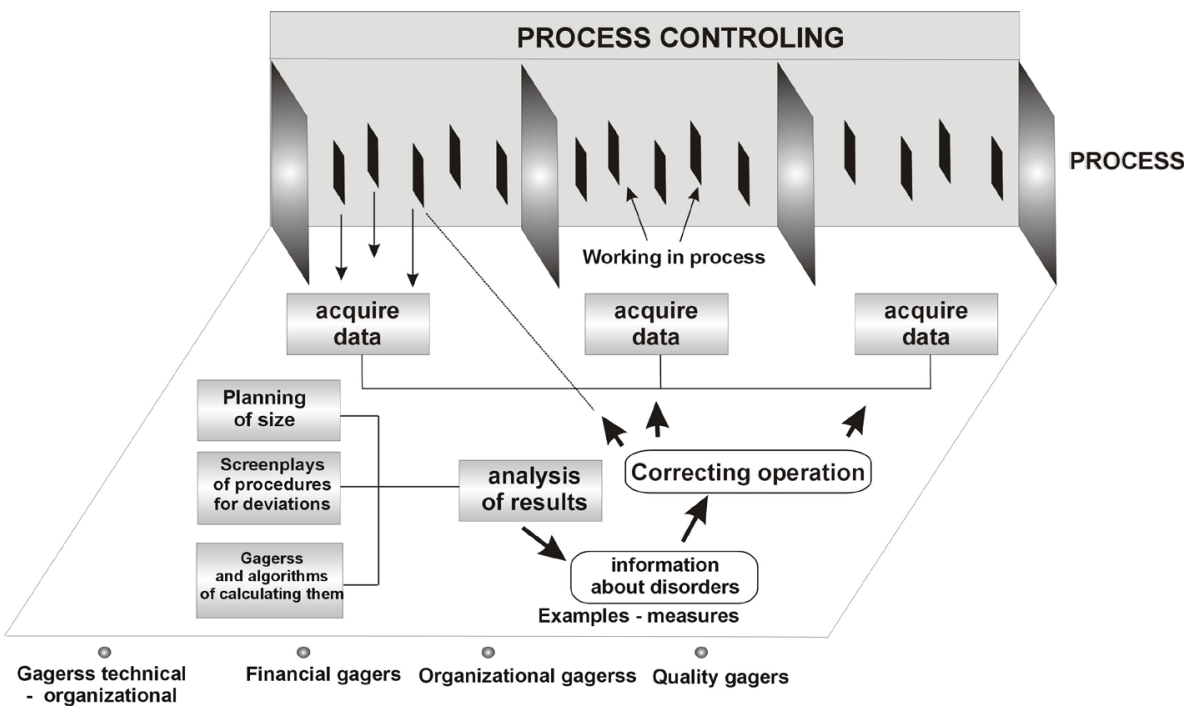

Figure 2. The main relations of the controlling system affecting the logistics processes of purchases and sales

The collection and analysis of all kinds of information is the basis of the controlling unit's operation. The type of information flow between the various departments of the company is of great importance for the method of production control. The flow of information in the organization affects, among other things, the state of stock and its relationship with the current production and purchases. Thanks to the available information, the controlling department analyzed the dependence of the production status on the stock level, human resources, development research, available technologies and the market situation. The level of coordination of the activities of the marketing department, production department and development department turned out to be very important. The coordinator here is the controlling unit. Controlling plays a significant role in quality assurance and optimizes the product control process.

The functioning of a company in a trial system with the use of controlling requires the introduction of absolute information discipline. Persons participating in these processes should inform about the degree of implementation of tasks on an ongoing basis, so that process managers have up-to-date information about emerging disorders. An example may be Fig. 2, where data is recorded as part of the activities carried out, which in turn creates the necessary basic information resource, for example, for the effective operation of controlling.

\section{Summary}

Controlling in logistics and quality, properly implemented in the company, manifests itself in two ways. On the one hand, it helps and enables the coordination of logistics and management processes with quality, with a special emphasis on planning and quality control of supply chains. Through the quality of production, it also works to increase the competitiveness of the offered products and increase the company's revenues. On the other hand, controlling is forcing processes to constantly manage the expenses incurred in the company and looking for an opportunity to reduce them. Therefore, controlling, by direct impact on expenses and indirectly on income, increases the profitability of the company.

The implementation of the company's process management system makes it possible to organize the company in terms of the processes carried out. The controlling system helps in 
filling that part of the management element, which has also been subordinated to the processes. A team that is built with the company's processes in mind must use simple tools that are best suited to its processes to ensure compliance in the company's "internal markets". The currently identified centers of responsibility in the casting production process mean that the final goods can be delivered at the right time, to the right place and possibly produced at a sufficiently low cost. The controlling system must adapt to changing internal customers and the conditions of the operations performed. Process controlling is intended to help in the complete shaping, control and evaluation of these processes. Further work is underway to find the appropriate explanatory factors describing the effects of the implementation of the processes and to capture their indicators appropriate to the form or measured quantity.

Logistics controlling presented in this article may be useful in various industrial areas, including hydraulics $[10,11]$ and heavy working machines $[12,13]$, corrosion protection [14], as well as production of machine parts $[15,16]$ and improvement of their properties [17]. It may also have a direct impact on the management of similar industrial processes [18], and require appropriate modifications in analytical research methods [19] even in biotechnology [20], especially those that use statistical methods [21,22].

\section{References}

[1] R. Wolniak, Operation manager and its role in the enterprise, Production Engineering Archives 24 (2019) 1-4. https://doi.org/10.30657/pea.2019.24.01

[2] A. Pacana, K. Czerwińska, Analysis management instruments of the causes of control panel inconsistencies in the gravitational casting process by means of quality, Production Engineering Archives 25 (2019) 12-16. https://doi.org/10.30657/pea.2019.25.03

[3] B. Jereb, J. Rosak-Szyrocka, Quality of investments in logistics, Production Engineering Archives 2 (2014) 6-8. https://doi.org/10.30657/pea.2014.02.02

[4] M. Nowicka-Skowron, R. Ulewicz, Quality management in logistics processes in metal branch, METAL $201524^{\text {th }}$ Int. Conf. on Metallurgy and Materials, Ostrava, Tanger, 2015, $1707-$ 1712.

[5] R. Ulewicz (eds.), Narzędzia jakości w praktyce. Poradnik dla biznesu, Czestochowa, SMJiP, 2018.

[6] P. Nyhuis, H.P. Wiendahl, Fundamentals of production logistic - theory, tools and applications. Berlin, Springer, 2009. https://doi.org/10.1007/978-3-540-34211-3

[7] H. Kerzner, Project management best practices: achieving global excellence. New York, Wiley, 2010.

[8] S. Kukla, Costs analysis of iron casts manufacturing. Arch. Foundry Eng. 12 (2012), 45-48. https://doi.org/10.2478/v10266-012-0034-9

[9] A. S. Polak. Quality controlling - trends. Problemy Jakosci 2 (2004), 18-21.

[10]P. Walczak, A. Sobczyk, Simulation of water hydraulic control system of Francis turbine. Proc. $8^{\text {th }}$ FPNI Ph.D Symposium on Fluid Power, 2014, art. V001T04A001. https://doi.org/10.1115/FPNI2014-7814 
[11] M. Domagala, H. Momeni, J. Domagala-Fabis, G. Filo, D. Kwiatkowski, Simulation of cavitation erosion in a hydraulic valve. Materials Research Proceedings 5 (2018) 1-6. https://doi.org/10.21741/9781945291814-1

[12] M. Domagala, H. Momeni, J. Domagala-Fabis, G. Filo, M. Krawczyk, J. Rajda, Simulation of particle erosion in a hydraulic valve. Materials Research Proceedings 5 (2018) 17-24. https://doi.org/10.21741/9781945291814-4

[13] P. Krawiec, A. Marlewski, Spline description of non-typical gears for belt transmissions. J. Theor. Appl. Mech. 49 (2011) 355-367.

[14] T. Lipinski, D. Karpisz, Corrosion rate of 1.4152 stainless steel in a hot nitrate acid. METAL 2019: $28^{\text {th }}$ Int. Conf. on Metallurgy and Materials, Ostrava, TANGER, 2019, 10861091. https://doi.org/10.37904/metal.2019.911

[15] T. Pieczonka, J. Kazior, A. Szewczyk-Nykiel, M. Hebda, M. Nykiel, Effect of atmosphere on sintering of Alumix 431D powder. Powder Metall. 55 (2012) 354-360. https://doi.org/10.1179/1743290112Y.0000000015

[16] J. Pietraszek, A. Gadek-Moszczak, The Smooth Bootstrap Approach to the Distribution of a Shape in the Ferritic Stainless Steel AISI 434L Powders. Solid State Phenomena 197 (2012) 162167. https://doi.org/10.4028/www.scientific.net/SSP.197.162

[17]D. Przestacki, R. Majchrowski, L. Marciniak-Podsadna, Experimental research of surface roughness and surface texture after laser cladding. App. Surf. Sci. 388 (2016) 420-423. https://doi.org/10.1016/j.apsusc.2015.12.093

[18] A. Pacana, L. Bednarova, I. Liberko, A. Wozny, Effect of selected production factors of the stretch film on its extensibility. Przem. Chem. 93 (2014) 1139-1140.

[19]L. Wojnar, A. Gadek-Moszczak, J. Pietraszek, On the role of histomorphometric (stereological) microstructure parameters in the prediction of vertebrae compression strength. Image Analysis and Stereology 38 (2019) 63-73. https://doi.org/10.5566/ias.2028

[20] E. Skrzypczak-Pietraszek, A. Urbanska, P. Zmudzki, J. Pietraszek, Elicitation with methyl jasmonate combined with cultivation in the Plantform ${ }^{\mathrm{TM}}$ temporary immersion bioreactor highly increases the accumulation of selected centellosides and phenolics in Centella asiatica (L.) Urban shoot culture. Engineering in Life Sciences. 19 (2019) 931-943.

https://doi.org/10.1002/elsc.201900051

[21] T. Styrylska, J. Pietraszek, Numerical modeling of non-steady-state temperature-fields with supplementary data. ZAMM 72 (1992) T537-T539.

[22] J. Pietraszek, E. Skrzypczak-Pietraszek, The optimization of the technological process with the fuzzy regression. Adv. Mater. Res-Switz. 874 (2014) 151-155. https://doi.org/10.4028/www.scientific.net/AMR.874.151 